\title{
44263 - EPIDURAL KETAMINE FOR POSTOPERATIVE ANALGESIA IN THE ELDERLY
}

\author{
Hanan El Shobary, McGill University Anesthesia, Montreal, QC, Canada; \\ Zainab Sonbul, Mansoura University, Anesthesia; \\ Thomas Schricker, McGill University, Department of Anesthesia;
}

BACKGROUND: In this pilot study we examined the use of epidural ketamine as an opioid alternative for postoperative analgesia in elderly patients undergoing major abdominal surgery. METHODS: With the approval of the local REB we approached patients older than 65 years scheduled for major abdominal surgery. After obtaining written informed consent 20 patients were allocated to receive a bolus of epidural bupivacaine $0.125 \%$ supplemented either with epidural ketamine 40mg (ketamine group) or epidural morphine $2 \mathrm{mg}$ (morphine group) 30 minutes before surgery. Postoperative analgesia and sedation were assessed using a verbal rating score ( $0=$ no pain, $1=$ mild pain, $2=$ moderate pain, $3=$ severe pain) and Ramsay's sedation score, respectively. At the patient's request five $\mathrm{ml}$ boluses of $0.125 \%$ bupivacaine together with ketamine $(2 \mathrm{mg} / \mathrm{ml})$ or morphine $(0.1 \mathrm{mg} / \mathrm{ml})$ were given until a pain score of two at rest was established. The incidence of postoperative nausea and vomiting (PONV) requiring treatment was recorded.

RESULTS: We approached and randomized 20 patients with 10 patients in each group. Mean age was $69 \pm 5$ years in the morphine group and $69 \pm 3$ years in the ketamine group. Pain scores immediately (0h) and (6h) after surgery were significantly higher in the ketamine group than in morphine group (0h: $2.5 \pm 2.0$ versus $0.0, \mathrm{p}=0.002 ; 6 \mathrm{~h}: 1.8 \pm 1.3$ versus $0.0, \mathrm{p}=0.001)$. None of the patients receiving epidural morphine requested a top up within the first 24 postoperative hours. Eight patients in the ketamine group required additional boluses. The total amount of epidural ketamine administered was $70 \pm 19 \mathrm{mg}$. Thirty minutes after the operation sedation score was higher in the morphine than in the ketamine group ( $4.1 \pm 1.2$ versus $2.7 \pm 0.5, \mathrm{p}=0.03$ ). In the morphine group three patients had PONV while in the ketamine group PONV was not observed. CONCLUSION: The results of this pilot study show that epidural ketamine, when compared to epidural morphine, is associated with less sedation and a smaller risk of PONV, but necessitates more frequent or continuous administration to achieve comparable analgesia. 